\title{
The Intention to Use Mobile Student Portal: A Mobile Human Computer Interaction Study in a University Context in Egypt
}

\author{
Ghada Refaat El Said \\ Department of Management Information Systems, Future University in Egypt (FUE), 90th Street, Fifth Settlement, \\ New Cairo, Egypt \\ Correspondence should be addressed to Ghada Refaat El Said; ghada.refaat@fue.edu.eg
}

Received 16 May 2018; Revised 13 June 2018; Accepted 7 July 2018; Published 24 July 2018

Academic Editor: Michael Vassilakopoulos

Copyright ( ) 2018 Ghada Refaat El Said. This is an open access article distributed under the Creative Commons Attribution License, which permits unrestricted use, distribution, and reproduction in any medium, provided the original work is properly cited.

\begin{abstract}
Mobile devices are increasingly being used as platforms for interactive services. However, factors affecting adoption of mobile services in some specific contexts, such as student portals, are still underresearched. This paper reports thematic analyses of semistructured interviews conducted with 52 undergraduate users of mobile student portal in a developing country. The results uncover design features affecting the use of mobile student portals, such as (1) Content Sharing, comprising an Integrative Design to share posts from the mobile portal to social media, (2) Personalized Content and Notification, for personalized notification based on student's academic status, (3) Location-Aware notification, providing location-based updates, (4) User Control, allowing to choose content formats and details level, and (5) Context Switching and Interrupted Behavior, leading to the need for displaying content in small, meaningful chunks to help pick up after interruptions of messages and calls. The findings suggest design recommendations for mobile student portal, in specific.
\end{abstract}

\section{Introduction}

The demand for a single integrated, easy-to-use, access to information applications and people within a network of users is increasing more and more. In the higher education context, mobile student portals are designed to increase accessibility to almost everything that a student associated with the campus needs. Once logged in, students have access to a variety of tools and information about their classes, teachers, office hours, test scores, extra credit, and extracurricular activities [1].

One obvious reason for universities to adopt mobile portals is to improve students' productivity and satisfaction, which is not always the case for reasons related mainly to portals design $[2,3]$. A considerable body of Information Systems research is currently taking place to explore acceptance factors in mobile web services adoption. There is also a growing concern that certain novel technologies, such as mobile web, may bring additional adoption issues that will not necessarily be uncovered by simply testing existing theories in a new context [3].
Another concern is the suitability of some design factors in particular application areas, such as university context, compared with other application areas [4].

Most of previous research in student portal context focused on web usability, mainly from desktop and laptop computers [5]. On the other hand, many of universities already built a separate mobile-optimised design for their student portal. As costly as it could be, these mobile sites, when implemented without assessing user preference, could hold usability challenges.

The study took place in Egypt, while classified as a developing country, has a high penetration of mobile devices [6]. A main aim of this research is to reveal mobile educational portal experiences for students from underresearched users. This paper begins by discussing past literature on adoption of mobile student portals, as well as previous research on student portals in developing countries. This is followed by a description of the methodology and data collection and a presentation of the results. Finally, the findings and their implications are discussed. 


\section{Background}

2.1. Previous Research on Mobile Student Portal. The last decade has seen substantial investments in technology infrastructure for higher education enterprises; mobile applications in specific are currently widely used in educational environments [7]. Resource constrains and accreditation requirements oblige higher education institutions to set their technology priority and select the most appropriate systems [8]. The immense availability of mobile devices among students offers opportunities to integrate them into educational context [7], taking an important role in the day-to-day life of students inside and outside the university campus. According to Zbick et al. [9], competitive advantages of mobile educational context portals, compared to desktop ones, are related to, namely, the mobility, portability, and the fact that it offers immediate help to students. Nevertheless, most of researches reveal dissatisfaction and negative student evaluation, for reasons mainly related to mobile portal design issues [9].

According to Zhang and Adipat [10], usability of mobile applications is an emerging research area that faces a variety of challenges due to unique features of mobile devices, such as changing connectivity conditions and mobility. Traditional guidelines and methods used in usability testing of desktop applications may not be directly applicable to a mobile environment [10]. Additionally, there is a severe shortage in the usability of mobile student portals. One of the few studies on mobile educational portal suggests that students' motivation can be stimulated if authenticity is introduced in the portal's content and design [7].

Previous research on student web portal interface in developing countries asserts weaknesses of these applications concerning usability and user acceptance. Student portals studied in these research works were lacking sufficient information, were anything but user-friendly, and were rarely updated [2].

A university's website satisfaction model was suggested by Rezaeean et al. [11]. They conducted a survey among 270 university students in Iran, and results suggest that greater innovation and perceived usability have significant impact on student's perceived usefulness, trust, and satisfaction in university portal [11].

In their usability evaluation study on student portal, Zazelenchuk and Bolind [12] raise the question of how well efficiency relates to user satisfaction for recent technologies, such as web-based portal applications. The usability study, conducted with 45 undergraduate university students, involves completing a series of tasks that required location information and personalizing the portal system [12]. The study reveals significant relationship between students' satisfaction and a number of design features of portals, such as portal responsiveness, interface organization and consistency, and timely informative and corrective feedback [12]. Booi and Dista [2] studied user acceptance of South African Universities Web Portal Interfaces. Their results suggest that interaction and invisibility are the most important factors affecting user acceptance and usability, respectively.

\section{Main Focus of the Article}

The current research aims to explore the factors that affect the use of mobile student portals. The focus was on user perception of portal features, as the main intent is to provide design recommendations to ensure better use of students' mobile portal. The study took place in the context of a developing country-Egypt.

In Egypt, the demographic of Internet users is young and active; with 45 million users, one half of them are under age 25 . Egypt has an Internet penetration rate of 52\%, representing a $1.68 \%$ share of world Internet users, and the largest population of Internet users in the Middle East and North Africa region [6]. Smart phone users in Egypt reached 25.8 million in 2018 and expected to reach 27.9 million in 2019 with a penetration rate of $31 \%$ [13]. Although the potential benefits of mobile web application for educational purposes are particularly high for economically and academically disadvantaged societies [14], many aspects of such platforms are developed without considering preferences of users from these societies. This article is aiming to reveal mobile student portals experiences for users from Egypt.

\section{Research Methodology}

4.1. Semistructured Interviews. This research represents a descriptive, qualitative study employing semistructured interviews with university undergraduates. Web service research has been undergoing a major movement toward quantitative approaches [4], where the semistructured interview techniques are most preferred for disclosure of selfreflected data from individual sources [15]. The mobile student portal of the university, where the interviewees are registered was used during discussions within the interviewees. In the selected university, all students are required to use the portal for academic registration each semester. The portal used in the current research is bilingual, students can select/switch between Arabic and English at any page of the portal. Thematic analysis of data collected during the interviews was used to draw out the main adoption themes.

4.2. Sample. The target sample for this study covers undergraduate university students. Convenience sampling was used due to the need to identify a study context in which there was a clear academic rationale to invite students to discuss the mobile portal provided by their university. In this research, undergraduates were full-time students from different specializations (finance, business, information technology, management, and marketing) enrolled in a private university in Cairo, Egypt. The sample includes 52 students who were willing to participate in an individual interviewing session. Gender was almost equally distributed throughout the overall sample ( 24 males and 28 females), and age range varied between 16 and 24 . Students were informed that this interview is part of a study aiming to better design their mobile portal. They were also informed of their right to withdraw from completing the interview at any time. No compensation was provided to students. 
4.3. Procedures. The interviews were conducted face-to-face by the author of this paper in the months of January and February 2018. An announcement was posted on the portal of the university, where the author works as teaching professor, asking for students who are frequent users of the student mobile portal to volunteer in a research concerning better design of mobile student portal. Volunteered students applied by e-mail and schedules were arranged for interviews at the university students' study room.

The interviewing sessions started by informing participants that the length of each session would be 30 to 40 minutes long and that they can stop the session at any time. With the participant's permission, interviews were recorded using a portable recorder. Data collection was completed by saturation, which occurs when a feeling of closure is obtained from noticing repeated information.

The interviews started with a guiding question: "What is your experience with the mobile student portal?" This question was followed by a series of reflective questions to elicit in-depth responses and derive implications for the practical experience with the portal. The questions aimed to investigate the participants' general experience, how much of the portal content they usually check, why and when they use the mobile version of the portal versus the desktop one, and what issues, if any, they experienced when working with the mobile portal, trying to link these issues with their use. Throughout the interview sessions, participants were asked to indicate what they like or dislike about their mobile student portal and to suggest ways to enhance it. Some of the questions used in the interviews included:

How frequent do you login to the mobile student portal?

When and where do you usually use the mobile portal and the desktop portal?

What data do you usually retrieve from the portal?

How do you evaluate the system in general?

What do you dislike the most about the system?

What do you like the most about the system?

What do you propose to be added to the system?

In general, interviewees did not have any problem comprehending the questions.

Interviews were conducted in Arabic language, the mother tongue of the interviewer (the author of this paper) and all of the interviewees. In the closing comments, interviewees were encouraged to add anything that was left unsaid in the session and they were thanked and informed that the interview was successfully completed.

4.4. Data Recording and Analysis. The sessions were recorded, transcribed, and coded through thematic analysis. The thematic analysis technique is widespread in analyzing qualitative data [16]. Unlike textual analysis, thematic analysis goes beyond counting phrases or words and moves on to identifying patterns, themes, across datasets, describing the phenomenon under investigation [17]. Through a process of six phases, thematic analysis creates meaningful patterns to identify unfolded themes emergent from the data [18]. In the first phase, the researcher becomes familiar with the dataset through several readings of the transcript of the collected data to identify repeating issues and patterns. In the second phase, codes were generated by labeling relevant words, phrases, sentences, or sections. Following the guidelines of Braun and Clarke [19], data can be found relevant to code because it is repeated in several places (e.g., the mobility issue of the mobile portal); it surprises the researcher (e.g., the idea to integrate the mobile portal with student own social media); the interviewee explicitly states that it is important (e.g., reliability); and it is referenced in the literature (as for the case of perceived value). These relevant codes are combined in phase three into overarching themes. Identifying a theme does not necessarily yield the frequency at which a theme occurs. Ideally, the theme will occur numerous times across the dataset, but a higher frequency does not necessarily mean that the theme is more important to understanding the data (e.g., student control features). The identified themes are reviewed in phase four, in which some existing themes can be grouped together (e.g., perceived value and reliability); others might be split into subthemes (such as course personalized notification was split into personalized content and location aware). This process is repeated until the researcher is satisfied with the thematic map. In phase five, themes are defined and given names, providing a full sense of the theme beyond surface meanings of the data. In phase six, results are reported by integrating themes to convey the story of the data in a logical manner. Interviews' quotes are included to provide sufficient evidence that themes within the data are relevant to the dataset. Conclusion is interpreted in light of results from similar previous studies and newly uncovered themes.

\section{Results and Discussion}

Based on thematic analysis of the interview sessions, a number of themes and associated categories were revealed concerning intention to use mobile student portal. Some of these themes support findings of previous literature; others were novel finding in the context of mobile human computer interaction, as discussed in the following sections.

5.1. Theme 1: Perceived Value. Values define the key features of the system that are appreciated by the target users; they represent the main reasons why the users are interested and intending to use a system. Defining the users' perceived values helps in focusing the design on the most essential features. The current research highlights the importance of perceived value as a broad mobile student portal use driver. During interviews, participants envisaged the student portal would provide value to them throughout: Reliability, Content Sharing, and Mobility, as discussed in the following sections.

5.1.1. Reliability. As alternatives to other students' information dissemination channels within their universities, participants of the current research expressed that mobile portals have the benefit that they are always available and accessed. Since 
students cited that they check their phones several times a day, for them, mobile student portals is the best way to keep up to date with what is going on in campus. All of the interviewees expressed the importance that the students' portal includes updated and comprehensive information, sufficient enough to rely on as the main source of information, as cited below in the following quotes:

"I am checking my mobile phone several times during the day and I rely on the mobile portal to get updated and comprehensive information about social and academic events in campus."

"I totally depend on the mobile portal to get updates about courses registration, drop and add, as well as students activities... I don't need any more to collect bits and pieces of data from students affair office, or the school bulletin board...."

5.1.2. Content Sharing. Content Sharing is explained by the interviewees as the preference to share posts from mobile student portal to other student's own account on social media. Some of the interviewees (13 out of the 52) expressed the need to be able to share the news and information from the portal to other students on the faculty Facebook, in case of student's activity announcement and academic deadlines. Few students expressed that sometimes they like to share videos, images, and text included in the portal to their own account on facebook.

"It would be great if I can share important news from the portal, such as academic calendar, and dates of social activities and events... and post it on the faculty facebook," as stated by an interviewee. A second interviewee expressed the preference to "When a celebrity visits the university, photos are posted on student's portal... I would be great if I am able to share photos, video, links from the portal to my facebook. ..."

Those interviewees expressed that their accounts on social media, most of the time, are open on their mobile, when accessing the student's portal, they like to easily share some posts from the portal to these accounts. The ability to share posts from the portal to social media, gives competitive advantage to the mobile portal, as explained by those interviewees.

5.1.3. Mobility. Mobility was expressed by interviewed students as the degree of connectivity that allows them to access the portal via mobile phones anywhere, anytime, and under various connectivity conditions. The highest majority (45 out of 52) praised the mobile portal as a movable source of information they can access anywhere and anytime. Many of the interviewed students mentioned that mobile portal already reduced their attendance in the faculty information office and student affair department. This suggests that mobility is a key factor affecting the use of mobile students' portal.

On the other hand, the frustration from loading photos and videos included in the mobile portal in public areas within and outside campus, with unreliable and low-speed Internet connectivity, was cited as the main reason for not using the mobile portal.
"I am checking the student portal from my phone on the run, in the university shuttle bus and between class breaks. This is great, but in areas with weak connectivity it freezes." expressed an interviewee. "In area with low Wi-Fi, on my smart phone, videos and large pictures won't load or won't even appear, this is very frustrating" as stated by an interviewee. This suggests that while the mobility feature is suggested to be an important antecedent of use for mobile student portal, it also can limit its use in cases of lowconnectivity conditions. Offline features can deal with this issue by giving users the option to download videos and large pictures beforehand with a reliable Internet coverage, to watch them later when they move to a nonreliable coverage. On the other hand, portal can be designed to save state and remember what users were doing when signals drop to accommodate users who might lose signals during browsing.

It could be concluded that mobility and Internet coverage would affect usage of the portal, though this could be somewhat handled by appropriate portal's design.

\subsection{Theme 2: Personally Relevant Content. Personalization} was perceived by the participants of the current research as the capability of portal to reflect the students' own personality, also the ability to display personalized content, based on individual student's location and academic status. During interviews, participants envisaged the student portal would provide personally relevant content throughout: Genuine Photos, Personalized Notification, and Location aware, as discussed in the following sections.

5.2.1. Genuine Photos. All of the interviewees explained that they would use the mobile portal more if it includes videos and photos from the students activities and events, not only the academic posts. Students' activities photos are kept on the university website and not the mobile portal. On the other hand, the majority of interviewed students (30 out of 52) complained that the current look of the portal does not reflect them, as most of the photos used in the portal interface are not genuine and are not for students from their university.

"What is the idea of using photos of American/European students, who do not look like us. We are all Egyptians here!. . It is true we are having few international students, but they are also from Africa. I expect to find photos of real students," as cited by a student.

The students expressed the need to feel that the portal reflects their identity, and they appreciated authentic photos, reflecting what they actually see in their campus.

5.2.2. Personalized Notification. Some interviewees showed preference that the mobile student portal provides personalized notification based on student's academic status and relevant deadlines. Examples of these personal notifications were given by the interviewees, as following: changes in the timetable of the student's specific bus, warning for the student's own absenteeism rate, deadline for registration and 
add and drop courses, and notification for events of the student's faculty or class.

5.2.3. Location Aware. Few users ( 8 out of 52) suggested that the mobile portal can provide location-award notification. The dynamically generated information based on the student's mobility within campus or on the way to campus is a feature that could be appealing to students. Some of the examples of location awareness were given by an interviewee, as following:

"Using Wi-Fi at different places on campus, I'd like to be notified about news related to the place... for example, in the library, to notify me of new book arrivals. In food court to notify me of meals new offers. Near the university theater, to notify me of events currently taking place...."

Another student suggested that this location-aware notification feature can be useful to inform students of working hours and rules of public places in campus, once they step in these places, such as library and computer labs.

5.3. Theme 3: User Control. User control is expressed by the current research participants as the extent to which mobile portal users can control content amount, whether detailed or brief, as well as enable or disable features such as location track and notifications. User control was primarily mentioned by interviewees who have extensive experience with web and mobile applications. The interviewees provided interesting ideas for adding more user control over the mobile portal, such as those discussed in the following sections.

5.3.1. User Control over Content. Students expressed that they use mobile for various purposes at the same time, with an interrupted and multitasking behavior; they expressed a preference for easy-to-scan small chunk content.

"With the mobile portal, I am not expecting overwhelming content, I expect small and meaningful chunks," as cited by an interviewee. "While checking the mobile portal, I

frequently get interruptions with text messages and calls, I also tend to switch to check my e-mails and Facebook, I need to be able to catch-up when I return back to the portal," as stated by another interviewee.

On the other hand, same students expressed that in some specific cases, they "rely on the mobile portal to get detailed and comprehensive information," and this is related to the Reliability theme cited above. Hence, many of the interviewees suggested a control over content, enabling the user to select between detailed versus brief text and text versus videos, for each content included in the mobile students' portal.

5.3.2. User Control over Features. While some of the interviewees who expressed the importance of getting location-related and academic-related notifications, as cited in the Personally Relevant Content theme discussed above. Many of those also suggested that these features be optional. It was recommended by those students that the user should have the option to enable/disable the location identification and academic status identification.

\section{Conclusion and Implications}

This exploratory study investigates factors affecting the intention to use mobile student portal for university students. The study was conducted in a university context in Egypt. The study aims to provide practical mobile student portal design guidelines for educational entities, designers, and implementers, to enhance students' willingness to use. Series of semistructured interviews were conducted with undergraduate of a private university in Egypt. Thematic analysis of the interviews revealed three themes (Perceived Value, Personally Relevant Content, and User Control); within these, a number of contributing items are suggested to affect students' intention to use mobile portals, as listed in Table 1. Some of these factors were identified in previous studies, such as Perceived Value [20, 21], Reliability [3], Mobility [8], and Location Aware [5]. Other factors were newly introduced in the mobile students' portal adoption context, such as Content Sharing, Personalization, and User Control. Additionally, some students' behaviors in mobile portals were newly discovered, such as the Context Switching and Interrupted Behavior. The current study provides a number of theoretical and practical contributions to the existing understanding of mobile student portal adoption, as in the following sections.

6.1. Theoretical Implications. This research provides a number of theoretical implications which contribute to the existing understanding of mobile portal adoption, as shown in the following sections.

6.1.1. Perceived Value. Perceived value was identified as an important determinant of intention to use mobile student portal. The construct was extensively discussed by all interviewees, supporting the applicability of previous findings on mobile application use to the mobile student portal context $[3,20,21]$. In the current study, authentic insights collected from the interviews suggested that reliability is considered as a value that mobile portal would provide to the users. As alternatives to other services, mobile services, in general, have the benefit that they are available most of the time, allowing to provide users with updated information [5]. In the student portal case, updated content would include opening and closure of courses registration, updated academic calendar, and lastminute changes to students' event schedules. Students use the portal usually at registration and exam time, and this is when there is need of updated, comprehensive, and sufficient information. If the students cannot rely on the mobile portal information to complete the task, they will look at it elsewhere. 
TABLE 1: Suggested factors affecting the intention to use mobile student portal.

\begin{tabular}{lc}
\hline Adopting factors & Contributing items \\
\hline Perceived value as discussed below: & $\begin{array}{c}\text { Reliability } \\
\text { Content Sharing } \\
\text { Mobility }\end{array}$ \\
\hline Personally relevant content & $\begin{array}{c}\text { Genuine Photos } \\
\text { Personalized Notification } \\
\text { Location aware }\end{array}$ \\
\hline User control & $\begin{array}{c}\text { User Control over Content } \\
\text { User Control over Features }\end{array}$ \\
\hline
\end{tabular}

6.1.2. Personally Relevant Content and Notification. Being on the top of personal communication devices, key values for mobile systems include personally relevant content and communication. Features such as personally relevant and interesting content and communication are highly valued. Individual notifications based on student's academic status, such as relevant deadline and warning, were cited as preferable features. Additionally, providing students with location-based information to notify students at a certain time at a certain location was suggested by a number of interviewees, as additional value of the mobile portal. Such construct may enrich the service, bring in additional users, and encourage a sense of community among users.

6.1.3. User Control. User control is expressed by participants of the current research not only as the extent to which they can chose between different alternatives of content format and details, but also to be able to switch on and off some of the portal personalized features, such as the location-aware notifications.

6.2. Practical Implications. Students in general are overconfident in their mobile-based web browsing abilities; nevertheless, the current research revealed some of their weakness, such as lower reading levels and impatience. These issues reduce students' task success and require simple, relatable student portal design. This study provides suggestions for designers of mobile student portals, to ensure better adoptions within students, and they are given in the following sections.

6.2.1. Redirect Mobile Users to the Mobile Site Version. The majority of participants indicated that in most cases, when they search for their student portal using their mobiles, search engines guide them to full site version instead of the mobile ones. Therefore, it is important to offer a clear link from the university full site to the mobile site for users who end up at the full site.

6.2.2. Clearly Identify Link to Student Portal on Every Page of the University Website. The link to student portal should be clearly visible on every page of the university website. Some of the participants indicate that they did not access the student portal from the university website, rather from internal pages via search.
6.2.3. Use Genuine Photos Reflecting User's Values. In the interviews, participants praised the fact that the university site includes photos and video gallery of sporting and art events. Two issues were raised concerning the use of photos. First, most of participants commented that photos about student life and activities are kept on the main home page of the university's website, and none are included in the student portal part of the site. Second, participants commented that they can easily tell the difference between genuine photos of real students in their university and advertising photos. Users appreciate photos that look authentic and representative of what they actually see in their university.

6.2.4. Design for Interruptive Behavior. Almost all participants expressed that their access to the student portal via their mobiles is been interrupted by text messages, calls, and message and e-mail alerts. Describing their interaction with the student portal as interrupted and multitasking, they expressed a preference for rapid scanning of content, with less effort. Display content in small, meaningful chunks with plenty of white space helps students retain information and pick up where they left off after the interruptions of text messages and phone calls.

A main challenge in mobile site design is to eliminate features and word count without limiting the selection of main tasks. A mobile site should have less information about each task, but the range of tasks should remain the same as that on the full site. On the other hand, most of the participants dislike tiny font sizes. Even though they're sufficiently sharp-eyed, most participants move too quickly and are too easily distracted to attend to small text.

6.2.5. Design for Mobility. Participants complained that the student portal includes lengthy videos, and with variable connectivity, uploading videos is very frustrating. Therefore, captions and a transcript of the video could be helpful in the mobile portal. The main issue with such mobility access is the frustration from loading materials, namely, videos, via smart phone in public areas with slow connectivity. Within the university, efforts should be made to ensure that Wi-Fi coverage and mobile Internet connectivity is adequate for students in campus. Killing time is often mentioned as one of the main contexts of use for the mobile Internet [5]. This motivation for use was also cited in the current study. Interviewees accessed the mobile portal when taking a break between lectures, waiting for the university bus, waiting for their friends, or sitting on the bus. Loading the portal needs to be fast on different connectivity conditions.

6.2.6. Follow the Student Changing Priorities along the Semester. Participants reported that with their mobile, they scan pages, rarely read text, and expect to find the need data in small comprehensive chunk. Therefore, it is recommended to identify the top tasks that students need to accomplish in different times along the semester, clearly show the task deadlines, and offer a step-by-step description of how to accomplish the task. Participants of the current 
research indicated that their priorities, when using the student portal, vary from one time to another along the semester. At the start of the semester, registration deadline, process, and fees should be the main icon on the screen, while on exam times, exam schedule should be the main icon. Depending on the seasonal priority of students along the semester, these priority tasks need to be clearly labelled and easy to spot.

6.2.7. Integrative Design and Content Sharing. Students are heavy users of social media with their mobiles. Integrative design with social media, Web 2.0 tools, and other web resources would be a good employment of web technology on mobile student portals, as suggested by an interviewee. Mobiles are personal communication devices and hence, services that enrich communication add good potential [5]. A suggestion was raised by an interviewee to integrate student portals with professional network, such as LinkedIn, and knowledge management of the university's industrial and academic partners. The integrative features are best to be designed in the mobile site as high majority of interviewees explained that they access their social media, read materials, and access their student portal via the same mobile device.

\section{Limitations and Future Work}

As with any empirical study, there are some limitations to the current research. One limitation is that the interviews sample was limited to the same geographical and cultural context. All participants were undergraduate students from a single university in Cairo, Egypt, which affects the generalization of the results. Egypt, though it is a developing country, owns a relatively high penetration of mobile technology, which might not be the case in other developing countries. Additionally, the private university, of which the student portal is used in this study, is still relying on manual systems in few of its process. For example, courses registration is done manually, as well as borrowing books from library. On the other hand, checking course schedule, downloading course materials, and getting course grades can be solely retrieved from the student portal. Hence, dependence of students on the portal is partial.

The interviewing method, used in this study, brought out users' authentic reactions and ideas about the system. However, the method does present limitations [4], as there are often differences between what users say about the system and what they actually do on the system. Hence, direct observation via usability testing or web analytic data on the usage of mobile portal might be sometimes needed to supplement interviews. It therefore remains a question for future research to explore the extent to which factors identified in this study will also hold for mobile university systems adoption for other samples and with other research tools. The implications of the current research suggest number of research questions which would be suitable for future quantitative examination. It would also be interesting to investigate some of the newly identified themes in a wider range of mobile technology applications.

\section{Data Availability}

The data used to support the findings of this study are available from the corresponding author upon request.

\section{Conflicts of Interest}

The author declares that there are no conflicts of interest.

\section{References}

[1] R. Katz, Web Portals and Higher Education: Technologies to Make It Personal, Educause and Nacubo, Jossy-Bass A Wiley Company, San Francisco, CA, USA, 2006, ISBN-13: 978-0787961718.

[2] V. Booi and G. Dista, "Usability and user acceptance of university web portal interfaces: a case of South African Universities," in Communications in Computer and Information Science (373), C. Stephanidis, Ed., pp. 91-95, Springer Publication, Las Vegas, NV, USA, 2013.

[3] S. Alfaresi and K. Hone, "The intention to use mobile digital library technology: a focus group study in the United Arab Emirates," International Journal of Mobile Human Computer Interaction, vol. 7, no. 2, pp. 23-42, 2015.

[4] N. Mallat, "Exploring consumer adoption of mobile payments: a qualitative study," Journal of Strategic Information Systems, vol. 16, no. 4, pp. 413-432, 2007.

[5] E. Kaasinen, "User acceptance of mobile services," International Journal of Mobile Human Computer Interaction, vol. 1, no. 1, pp. 79-97, 2008.

[6] Internet Live Stats, World Wide Web Consortium (W3C), 2018, http://www.internetlivestats.com.

[7] S. Ruth, "Is E-learning really working? The trillion-dollar question," IEEE Internet Computing, vol. 14, no. 2, pp. 7882, 2010.

[8] G. R. El Said, "Understanding how learners use massive open online courses and why they drop out: thematic analysis of an interview study in a developing country," Journal of Educational Computing Research, vol. 55, no. 5, pp. 724-752, 2017.

[9] J. Zbick, I. Nake, M. Milrad, and M. Jansen, "A web-based framework to design and deploy mobile learning activities: evaluating its usability, learnability and acceptance," in Proceedings of the IEEE 15th International Conference on Advanced Learning Technologies (ICALT), pp. 88-92, Hualien, Taiwan, July 2015.

[10] D. Zhang and B. Adipat, "Challenges, methodologies, and issue in usability testing of mobile applications," International Journal of Human Computer Interaction, vol. 18, no. 3, pp. 293-308, 2015.

[11] A. Rezaeean, S. Bairamzadeh, and A. Bolhari, "The importance of website innovation on Students' Satisfaction of University," World Applied Sciences Journal, vol. 18, no. 8, pp. 1023-1029, 2012.

[12] T. W. Zazelenchuk and E. Bolind, "Considering user satisfaction in designing web based portals," Educause Quarterly, vol. 26, no. 1, pp. 35-43, 2003.

[13] Statista, The Portal of Statistics, 2018, http://www.statista.com.

[14] C. Zhenghao, B. Alcorn, G. Christensen, N. Eriksson, D. Koller, and E. J. Emanuel, Who's Benefiting from MOOCs, and Why, 2015, https://hbr.org/2015/09/whos-benefitingfrom-moocsand-why. 
[15] H. Mariampolski, Qualitative Market Research, Sage Publications, Thousand Oaks, CA, USA, 2001.

[16] P. Yu and T. Hai, "A focus conversation model in consumer research: the incorporation of group facilitation paradigm in in-depth interviews," Asia Pacific Advances in Consumer Research, vol. 6, pp. 337-344, 2005.

[17] G. Guest, Applied Thematic Analysis, Sage Publications, Thousand Oaks, CA, USA, 2012.

[18] H. R. Bernard and G. W. Ryan, Analyzing Qualitative Data: Systematic Approaches, Sage Publications, Thousand Oaks, CA, USA, 2009.

[19] V. Braun and V. Clarke, "Using thematic analysis in psychology," Qualitative Research in Psychology, vol. 3, no. 2, pp. 77-83, 2006.

[20] D. Mugo, K. Njagi, B. Chemwei, and O. Montanya, "The technology acceptance model (TAM) and its application to the utilization of mobile learning technologies," British Journal of Mathematics and Computer Science, vol. 20, no. 4, pp. 1-8, 2017.

[21] J. Dong, H. Yin, L. Yongqiang, H. Li, and W. Wang, “TAM: a transparent agent architecture for measuring mobile applications," Computing in Science and Engineering, vol. 19, no. 1 , pp. $54-61,2017$. 


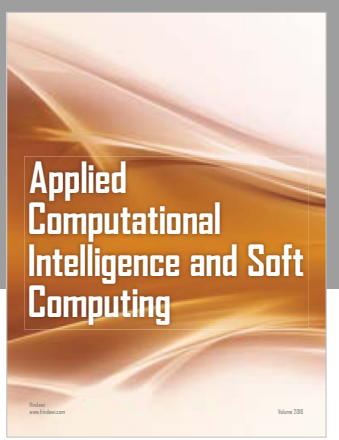

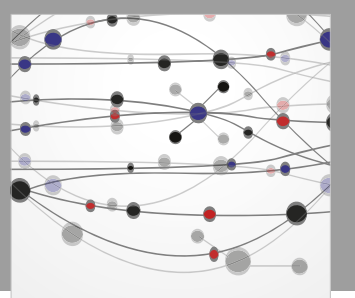

The Scientific World Journal
Submit your manuscripts at

Computing
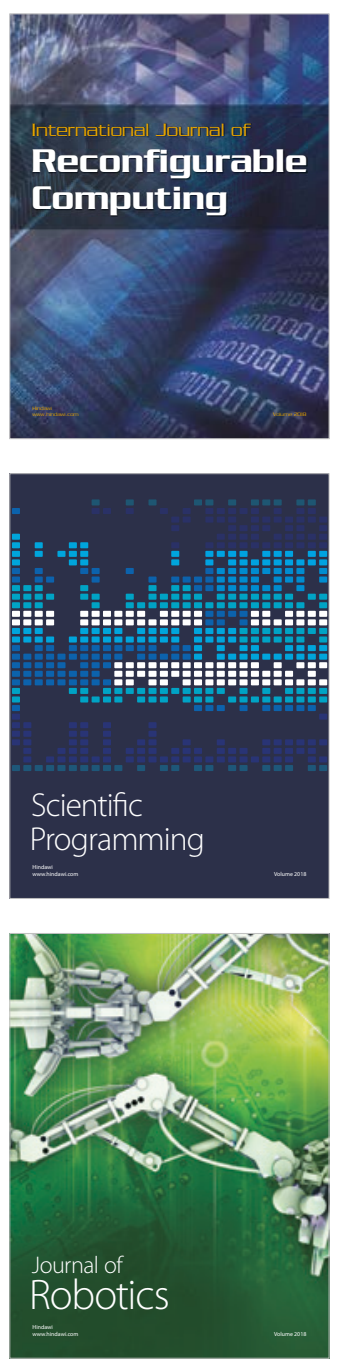

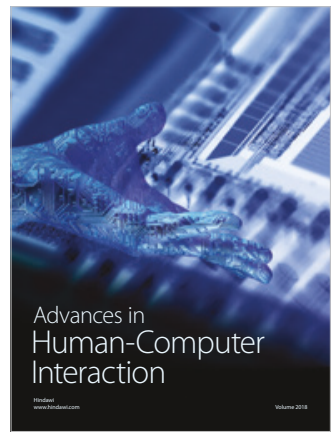

Human-Compute

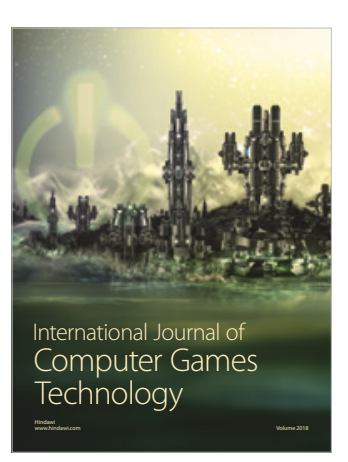

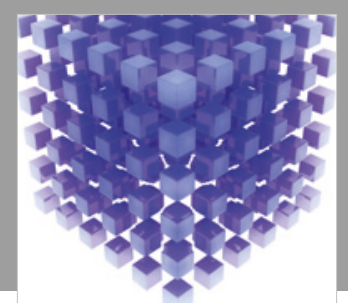

Mathematical Problems in Engineering

\section{Engincering}
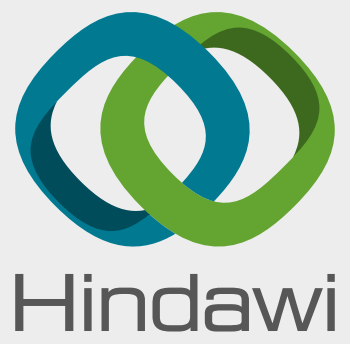

www.hindawi.com
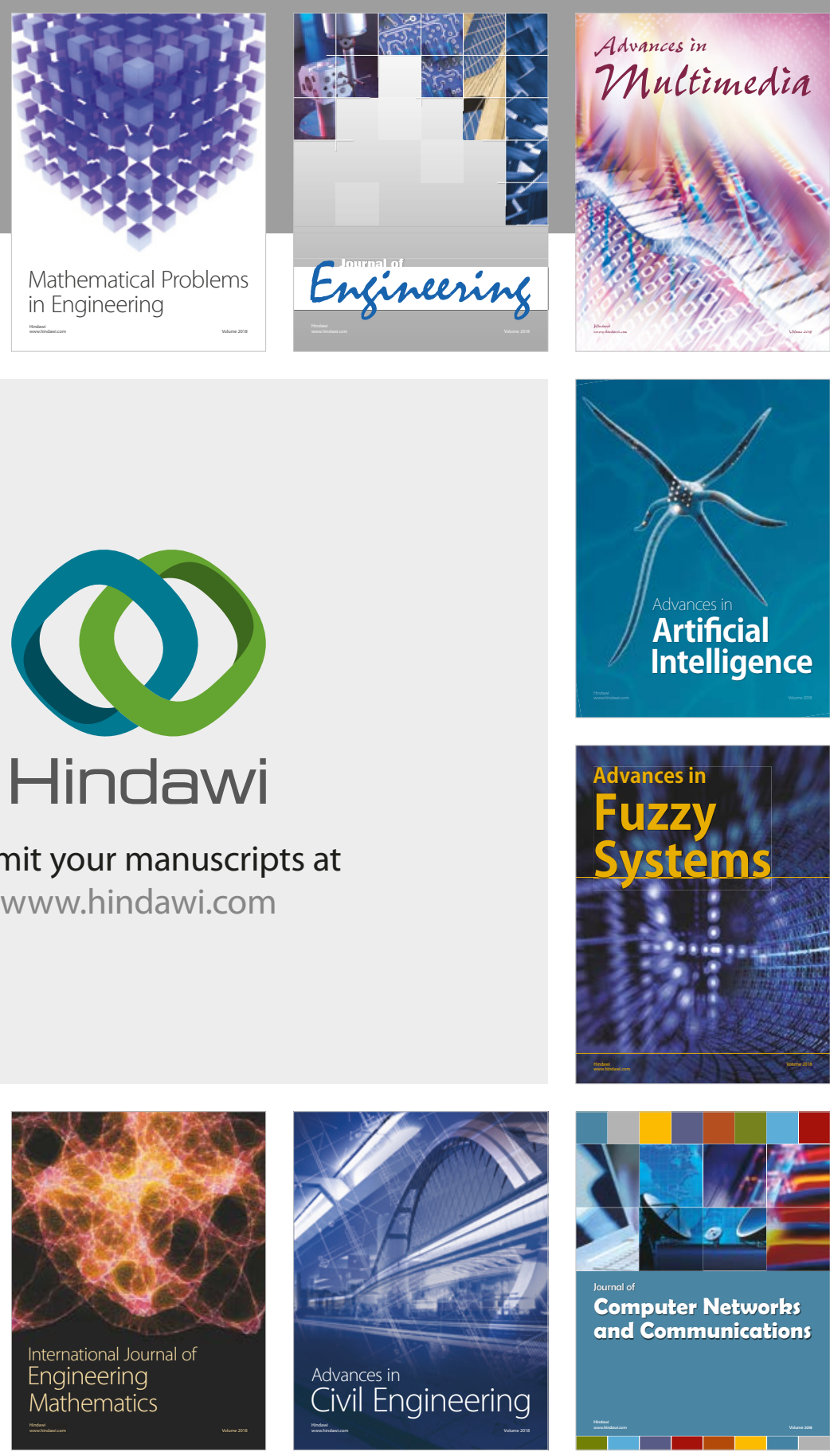

Computer Networks and Communications

Multimedia
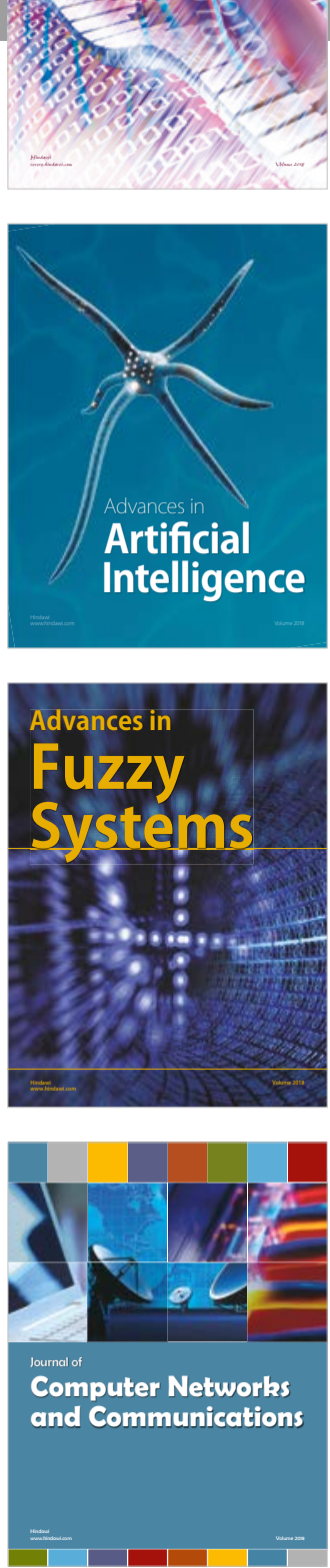

Advances in

Modelling \&

Simulation

in Engineering

interaction

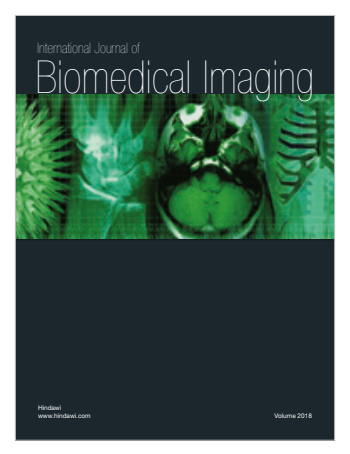

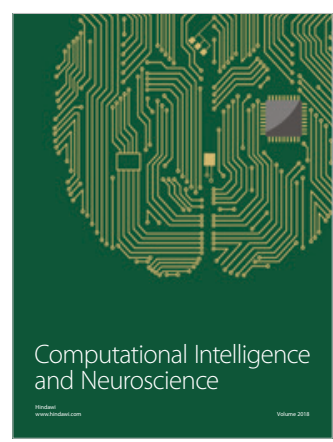

